\title{
Gobierno Municipal y Fiestas Religiosas. La intervención del Ayuntamiento de El Puerto de Santa María en la Festividad de la Virgen de los Milagros, Patrona de la localidad (1675-1825)
}

\author{
JESUS M. GONZALEZ BELTRAN
}

Una de las características peculiares del Antiguo Régimen, aunque no exclusiva de este periodo histórico, es la tradicional unión del trono y del altar, de lo civil y lo religioso. Una unión, no exenta de fricciones, cuya finalidad era la de asegurar el mantenimiento del orden socio-político existente. En lo social la preponderancia de los grupos privilegiados (nobleza y clero) sobre el resto de los grupos componentes de la sociedad. En lo político el predominio del absolutismo monárquico sobre otra cualesquiera forma de gobierno de carácter más progresista (1).

En:el ámbito local también se aprecia esta estrecha relación entre el poder civil, representado por el concejo o ayuntamiento, y el poder religioso, que aparece resumido en el cabildo eclesiástico. El concejo municipal colabora, la mayoría de las veces económicamente, con la Iglesia para que ésta pueda desarrollar sus funciones "sociales" (actividades educativas, hospitalaria y benéfica), a la vez que establece el marco legal en el que las mismas se deben llevar a cabo. Los eclesiásticos, por su parte, coadyuban a sostener el orden público, predicando al pueblo sumisión y resignación, e inciden en la administración local marcando y-o sancionando, por medio de pareceres o dictámenes morales, las líneas de actuación del ayuntamiento (repartimientos de pan, prohibición de diversiones públicas, legalidad de las contribuciones,...).

En el área de gobierno municipal en la que más claramente se puede observar esta profunda relación entre lo secular y lo religioso es en la encargada de la organización de. las fiestas locales. En efecto, hablar de festejos públicos en la edad moderna es hablar, salvo escasas excepciones (fiestas relacionadas con la monarquía: sucesos que afectan a la familia real, victorias militares, firmas de tratados internacionales,...), 'de festividades religiosas. La participación del cabildo

(1) Alvarez Santaló señala la extrapolación de elementos de la conducta religiosa a otros niveles de la vida social, en especial a la política. ALVAREZ SANTALO, L.C.; BUXO, M Jesús; RODRIGUEZ BECERRA, S. (Coords): La religiosidad popular. III. Hermandades, Romerias y Santuario, Barcelona, 1989, p. 8.

DOI: http://dx.doi.org/10.25267/Trocadero.1995.i6.04 
eclesiástico en ellas no necesita explicación. Pero al ayuntamiento, ¿qué le mueve a intervenir en estas fiestas de iglesia?.

En primer lugar, se trata de actos públicos que se desarrollan en las calles y plazas de la población, y en las que participa la mayoría del vecindario. Es decir, a pesar de su carácter sacro tienen lugar en parajes no sagrados y con la afluencia de los elementos no eclesiásticos de la localidad. Ambos, lugares y personas, caen bajo la jurisdicción del cabildo municipal (2). Se trataría, por tanto, de una intervención por razones de tipo legal o jurídico.

En segundo lugar, el ayuntamiento organiza, participa o colabora en los festejos religiosos y profanos con la finalidad subjetiva de reforzar el prestigio social y el poder de los miembros que lo componen. En estos actos, preferentemente en las procesiones religiosas, los capitulares se muestran a los vecinos como el grupo dirigente de la sociedad y el detentador de la autoridad en la localidad. Los festejos cumplen, de esta forma, una doble función: por una parte, sirven como escaparate social y, por otra, recuerdan al vecindario quienes son los individuos que monopolizan y controlan el gobierno municipal. Tenemos, pues, unas razones de caracter socio-político.

Por último, el ayuntamiento interviene en la organización de los festejos religiosos como contrapartida a la ayuda financiera que, en muchos casos, aporta para que éstos puedan llevarse a cabo con la compostura y boato necesarios (3). Nos encontramos, por tanto, ante razones de tipo económico.

En resumen, podemos afirmar que el ayuntamiento o concejo local interviene en los festejos en general y en los religiosos en particular, además de por las razones subjetivas de carácter socio-político, por otras más prácticas como las jurídicas, salvaguardar la legalidad y el orden de los actos, y las económicas, sufragar el total o parte de los gastos ocasionados por unas fiestas que, ante todo, y por encima de lo religioso, tienen un marcado cariz popular (4).

En el presente trabajo vamos a analizar la intervención del ayuntamiento o concejo municipal de El Puerto de Santa María en la que podemos calificar como

(2) Es también Alvarez Santaló el que indica que las devociones públicas y organizadas, como conductas masificadas, "han despertado la atención de los poderes (se entiende públicos) para utilizarlas, manipularlas, impedirlas, promocionarlas, desconfiar o apasionarse con elias". Ibidem.

(3) CASATILLO DE BOVADILLA, Jerónimo: Politica para corregidores y señores de vasallos en tiempos de paz y de guerra y para jueces eclesiásticos y seglares, y de sacas, aduanas y de residencias $y$ sus oficiales, $y$ para regidores $y$ abogados, $y$ del valor de los corregimientos $y$ gobier nos realengos y de las órdenes, Amberes, 1704 (redactado a finales del siglo XVI), Edición facsimil por el I.E.A.L., Madrid, 1978, Vol. II, p. 580, señala "entre los diferentes gastos a que pueden aplicarse los bienes de propio, el pago de salarios a músicos y menestriles para las fiestas del Santísimo Sacramento y otras públicas que tienen las ciudades". Ya en el siglo XVIII, SANTAYANA, Lorenzo de: Gobiemo politico de los pueblos de España, Zaragoza, 1742, Edición facsímil por el I.E.A.L., Madrid, 1978, p. 80, indica como destino de los caudales de propios el subvenir a los gastos de las fiestas de iglesia, pero ello por costumbre, no por reglamentaciôn legal alguna.

(4) Sobre la religiosidad popular, además de la obra de conjunto ya nombrada, La religiosidad popular..., tenemos el estudio de CARO BAROJA, Julio: Las formas complejas de la vida religiosa (siglos XVI y XVII), Madrid, 1985; y la obra de CHRISTIAN, Jr., William A.: Religiosidad local en la España de Felipe II, Madrid, 1991, (1ª edición inglesa en 1981). 
la fiesta religiosa más importante y significativa de todas las que se celebran en la localidad: la de la VIRGEN DE LOS MILAGROS, Patrona de la ciudad (5).

El marco histórico en el que se sitúa nuestro estudio es el del siglo XVIII, pero con prolongaciones hacia los siglos XVII y XIX. En concreto, nos moveremos entre los años 1675 , primero del que tenemos noticias más completas sobre la festividad de la Patrona, y 1825, en plena época de fricciones entre un absolutismo en decadencia y un liberalismo en alza.

La investigación se presenta dividida en dos grandes apartados. Primero veremos cómo organiza el ayuntamiento la fiesta de la Virgen de los Milagros y los problemas que se derivan de ello; en especial los enfrentamientos que se producen con el otro cabildo organizador, el eclesiástico. Y después, analizaremos la cuestión económica de la festividad, quizás el aspecto menos sagrado pero el más imprescindible para su ejecución.

\section{A. ORgANIZACION DE LA FESTIVIDAD DE LA VIRGEN DE LOS MILAGROS POR EL CABILDO MUNICIPAL. LOS PROBLEMAS CON EL CLERO}

El ayuntamiento de El Puerto de Santa María, como institución que representa a la ciudad y sus habitantes, colaboraba (organizando o financiando) y asistía a un número determinado de fiestas religiosas que se celebraban en la localidad, en concreto ocho, a saber: Nuestra Señora de los Milagros, Patrona de la ciudad; San Sebastian, Patrono; San Francisco Javier, Patrono; Triunfo de la Santa Cruz, por voto; Nuestra Señora de la Merced, por voto; Inmaculada Concepción, por real orden; Candelaria, por voto; y las Funciones de Semana Santa (6).

La participación del cabildo municipal en la festividad de la Virgen de los Milagros aparece regulada, por vez primera, en las constituciones de la cofradía de dicha Santa Imagen del año 1605 (7). En estas constituciones se establecía la obligación por parte de los dos cabildos, el secular y el eclesiástico, de alternarse cada año en la mayordomía de la mencionada cofradía. Es decir, un año correría con los gastos de la festividad, y por lo tanto con la organización de la misma, el ayuntamiento y al siguiente lo haría el clero; y así sucesivamente.

Esto era lo estipulado, pero la realidad no se ajustaba a ello. La falta de documentación relativa al siglo XVII nos impide conocer fielmente los datos sobre la organización y financiación de la fiesta de los Milagros en dicho periodo histórico. Un acuerdo municipal ya del siglo XVIII, en concreto de 1731, nos desvela algo el misterio. En dicho acuerdo se dice que la costumbre era que...

"el sr. corregidor y el sr. vicario, con su acostumbrado celo, soliciten persona devota, eclesiástica o secular, según la alternación tocare, que se haga cargo

(5) Sólo la fiesta del Corpus Christi competía en suntuosidad con la de los Milagros. Durante le siglo XVII la primera fue más relevante, pero pasó a un segundo plano en el siglo XVIII, una
centuria de gran impacto mariano.

(6) La asistencia limitada a estas ocho festividades se acordó por el cabildo municipal en 1729. Archivo Municipal de El Puerto (A.M.P.), Actas Capitulares (A.C.), cabildo 20-VI-1729, f. 69.

(7) No hemos podido consultar directamente esta fuente documental. Las noticias que sobre ella tenemos aparecen en A.M.P., A.C., cabildo 21-VII-1735, ff. 139-141. 
de la octava de Nuestra Señora y hallándola, la que así fuere, tenga facultad absoluta de nombrar los adjuntos que fuere su voluntad y regir la función con libre albedrío" (8).

Así pues, era costumbre que los cabildos secular y eclesiástico declinaran sus competencias en la organización de la fiesta en algún vecino particular. Este podía disponer los actos festivos con plena libertad; pero también, y lo que es más importante, debía sufragar con sus caudales y las limosnas que obtuviera mediante una cuestación pública los gastos que los festejos originaran. Mientras que el desembolso se mantuvo en un nivel aceptable fue posible encontrar particulares que se hicieran cargo de la mayordomía de la cofradía de la Virgen de los Milagros. Sobre todo si se tiene en cuenta la proyección social y el prestigio que alcanzaba ante sus convecinos este particular (9). Pero ya en el siglo XVIII, al dispararse los gastos, se hizo difícil encontrar personas para ocupar la mayordomía de la cofradía, sobre todo en los años de situación económica desfavorable (10). Es por ello, por lo que el cabildo municipal acuerda en 1731 que...

"no hallándose persona que se dedique a este culto (...) recaiga el octavario en el cabildo a quien tocare la alternación aquel año para hacerlo a su costa. En el que así tocare a la ciudad (ayuntamiento) haga el octavario por sus diputados de fiestas, acompañándose con los que tuviere nombrados el Ilustre clero. Y siendo de éste la función tenga la recíproca correspondencia de acompañar sus diputados con los de fiestas de la ciudad, guardándose el estilo de solicitar las limosnas y dotaciones y usar de los demás medios convenientes al mayor culto de Nuestra Señora y lucimiento de su octavario" (11).

Según hemos podido comprobar, a partir de 1731 y hasta el final del periodo estudiado, ningún particular se hizo cargo de la mayordomía de la cofradía y por lo tanto de la organización de la fiesta. Ello significa que, en virtud del acuerdo capitular al que hemos hecho referencia, que no hacía sino sancionar lo establecido en las constituciones de 1605 , cada año uno de los dos cabildos tuvo que organizar y correr con los gastos de la festividad de los Milagros.

El año que le correspondía al ayuntamiento una comisión compuesta de dos capitulares, los diputados de fiestas, se encargaría de todo lo referente a los actos programados, siendo ayudada, en especial en la solicitud de limosnas, por otros dos diputados del clero. El ayuntamiento en pleno examinaría los proyectos y realizaciones de los diputados de fiestas, aprobando o rechazando lo que creyera conveniente. Es decir, la diputación gozaría de cierta libertad de maniobra, pero siempre bajo la tutela del ayuntamiento, que es el que en última instancia decide.

(8) A.M.P., A.C., cabildo 1-VIII-1731, f. 224.

(9) Todavía en el siglo XX, en poblaciones pequeñas, persiste la costumbre de que un individuo acaudalado de la localidad corra con el "gasto" de algunas fiestas religioso-populares. CHECA OLMOS, Francisco: "El ciclo festivo en Lanteira (Granada)", en ALVAREZ; BUXO; RODRIGLEZ, Op. cit., Vol. III, pp. 70-95, nos ofrece ejemplos de ello.

(10) Dos casos. Nadie se ofreció para ocupar la mayordomía en 1720 y tampoco en 1730. A.M.P., A.C., cabildo 6-VIII-1720, f. 97 y cabildo 6-II-1730, f. 7.

(11) A.M.P., A.C., cabildo 1-VIII-1731, f. 224. 
Este cambio, acaecido en 1731, debe ponerse en relación con el hecho de que en dicho año tomaron posesión de sus cargos los nuevos capitulares de El Puerto de Santa María tras la incorporación de la ciudad a la Corona (12). Estaba claro que estos individuos, que accedian al gobierno municipal mediante la compra de los oficios públicos, no querían compartir con otros convecinos el "deber y el privilegio" de la organización de la fiesta patronal; especialmente, porque ello significaba compartir también el honor y el prestigio.

Ahora bien, el ayuntamiento no quedó solo en la tarea organizadora de la festividad de la Virgen de los Milagros. El cabildo eclesiástico, el clero, se reservaba la disposición del festejo uno de cada dos años. La convivencia no estuvo exenta de fricciones, ocasionadas por la actitud orgullosa y arrogante de ambos cabildos, principalmente del secular, que, apoyándose en la fuerza de su mayor poder económico, las rentas de propios y arbitrios municipales, intentaba desplazar al eclesiástico, a pesar del carácter religioso de la fiesta.

En 1736 se dio el primer enfrentamiento entre el ayuntamiento y el clero, motivado por problemas de protocolo en la procesión del Corpus. La indisposición continuaba aún en septiembre cuando la celebración de la festividad de la Patrona. El cabildo municipal acordó no asistir a los oficios religiosos que se celebraban en el interior de la iglesia, jurisdicción del clero, pero sí participaría en la procesión, el escaparate social, aunque "incorporándose en ella a la puerta de la iglesia" (13). Es decir, en la calle, jurisdicción concejil. Estas discordias se solventaron tras la intervención del mismísimo arzobispo de Sevilla en calidad de árbitro imparcial en enero de 1737.

A pesar de la paz, el antagonismo entre los dos cabildos continuaba subyacente y dispuesto a surgir en cualquier momento. Así ocurrió en 1742, cuando el ayuntamiento envió un escrito a los eclesiásticos en el que criticaba a los diputados del clero por, haberse excedido en sus funciones en la última festividad de 1741. A lo que se añadía la negativa a aportar 400 reales de limosna para la octava de la Patrona, tal como era costumbre todos los años, alegando los "graves empeños" que padecían los caudales públicos. Ahora bien, el cabildo municipal apostillaba, en relación con el tema económico, que “...siempre que quiera excusar el clero las fatigas y cuidados de la octava, el noble ayuntamiento está pronto a tomarla sobre sí todos los años". Tras deshacerse de la participación de los vecinos potentados en la festividad de la Virgen, los capitulares portuenses pretendían hacer lo mismo con el clero.

El cabildo eclesiástico se indignó y amenazó con "no mezclarse en función ni fiesta que haga dicha noble ciudad". De todo lo representado por los gobernantes municipales se extrañaba, especialmente, del hecho de que, por un lado, se negara a aportar los 400 reales de limosna por falta de caudales y, por otro, se ofreciera a hacerse cargo todos los años de la octava. Por lo que descubrían que el ayuntamiento "sólo experimenta necesidad cuando este ilustre clero está de

(12) Sobre la incorporación de la ciudad, que en 17.29 deja de pertenecer al duque de Medinaceli, y los individuos que obtienen los oficios capitulares mediante servicios pecuniarios, véase GONZALEZ BELTRAN, Jesús Manuel: El cabildo municipal de El Puerto de Santa María (1725-1734). Un estudio de la institución en su tránsito de señonio a realengo, Jerez de la Fiontera, 1989 (publicada, en verdad, en 1994).

(13) A.M.P., A.C., cabildo 4-IX-1736, ff. 175-176. 
por medio, respecto a que quedando solo y sin tales acompañados, no encuentra estorbo para facilitar arbitrios y aprontar medios para costear dicha octava todos los años".

En un ataque directo a los capitulares portuenses los acusaban de no aportar dinero propio para sufragar la festividad de la Patrona, sino que utilizaban (entendamos de forma legal) el caudal común y de todo el pueblo, mientras que ellos, los eclesiásticos, costeaban la octava con los caudales propios de cada miembro del clero. A pesar de lo cual, añadían vehementemente,

"no se excusaran de hacer la octava siempre y todos los años, sacrificando sus haberes en obsequio de su Madre y Señora Patrona, a quien con profundo rendimiento venera. Y cuando de suyo le falte para tan santo fin, saldrán los eclesiásticos, aunque sea de rodillas, a pedir sus limosnas por todo el pueblo" (14).

Afortunadamente, todo el enfrentamiento quedó sólo en el intercambio de escritos, algunos con un tono bastante subido y alterado, sosegándose las posturas tras diversas reuniones pacificadoras. A partir de este momento las relaciones clero-gobierno municipal serán más fluidas y las discordias, sólo dos entre 1742 y 1825, se solventarán con relativa facilidad (15).

A los organizadores tradicionales, ayuntamiento y clero, se va a unir, a partir de 1746 , un nuevo copartícipe: la archicofradía de las esclavas del Santo Rosario de María Santísima de los Milagros.

El 14 de julio de 1746 dicha archicofradía, por medio de su hermana mayor y hermanas secretarias, las sras. $D^{\mathrm{a}}$ Petronila Pineda, $\mathrm{D}^{\mathrm{a}}$ Josefa Argandoña y $\mathrm{D}^{\mathrm{a}}$ Bárbara de Winthuisen (16), solicitaron al ayuntamiento organizar los actos a celebrar en uno de los días de la octava según les permitieran "sus posibilidades". Los capitulares portuenses aceptaron lo pedido y acordaron que dichas hermanas se hicieran cargo del culto "el domingo infraoctavo, día en que se celebra el Dulce Nombre de María, por ser más propio a la fervorosa devoción de dicha esclavitud" (17).

Ahora bien, en dicho acuerdo no se especificó si la concesión se hacía de forma temporal o a perpetuidad, por lo que, en 1750, cuando la archicofradía pidió un testimonio del tácito convenio para organizar los actos de la octava el día 12 de septiembre a perpetuidad, el ayuntamiento negó la existencia de tal convenio y sus miembros se dividieron a la hora de decidir sobre la cuestión. Se

(14) Todo lo relacionado con este enfrentamiento de 1742 en A.M.P., Papeles Antiguos (P.A.), Apéndice Leg. 42.

(15) La primera discordia tuvo lugar en 1757 a raíz del nombramiento del capillet-tesorero de la Virgen de los Milagros que el clero quería arrogarse exclusivamente y que al final eligieron entre cuatro diputados (dos del ayuntamiento y dos eclesiásticos). A.M.P., A.C., cabildo 11VIII-1757, f. 132; 13-X-1757, f. 188; y 22-XII-1757, f. 211 v. Y la segunda en 1795 al no especificarse en las esquelas de la fiesta la intervención del cabildo eclesiástico. A.M.P., A.C., cabildo 28-VII-1795, f. 162.

(16) Se trata de las esposas de personajes influyentes de la localidad, en concreto de D. Francisco Javier Winthuisen Ticio, D. Baltasar de Eraunzeta y D. Alonso Navarro. Datos obtenidos de los libros de matrimonio de la Iglesia Mayor de El Puerto.

(17) A.M.P., A.C., cabildo 14-VII-1746, f. 107. 
hizo necesario recurrir a una votación, cuyo resultado fue, por mayoría de 8 a 3 , la de conceder el derecho a las esclavas de la Virgen de los Milagros para disponer por siempre los actos de la octava del día 12 de septiembre, aunque con las obligaciones de no sobrepasar los 600 reales de gastos ni la suntuosidad y boato de los restantes días de la octava (18). El ayuntamiento cedía, en lo cual puede tener relación el hecho de que varías de las esposas y otros familiares femeninos de los capitulares fuesen hermanas de la archicofradía, pero procuraba seguir manteniendo un estrecho control sobre todos los actos a celebrar en la octava, los organizase o no directamente la institución concejil.

Una vez probada y justificada la participación del cabildo municipal en la festividad de la Patrona, nos queda por ver en que consistía la intervención concejil. Por una parte organiza toda una serie de actos que discurren desde la víspera de la fiesta al último día de la octava. Por otra, corre con todos los gastos ocasionados por esos actos y otras medidas de caracter público relacionadas con los mismos. La parte financiera la examinaremos detenidamente en el siguiente apartado de este trabajo, ahora nos centraremos en la labor organizadora.

Ya hemos dicho que los años en que el ayuntamiento se hacía cargo de la fiesta y octava de la Patrona eran dos de sus miembros, los componentes de la diputación de fiestas, los que, bajo la tutela de la corporación en pleno, organizaban todos los actos y fiscalizaban su desarrollo.

La primera tarea de la diputación era la de elaborar el programa de actos, para lo cual contaría con la colaboración de los diputados del clero. En el siglo XVIII se implantó la costumbre de imprimir dichos programas, para la mayor información de los vecinos, así como unas pequeñas esquelas o estampitas que se entregaban a aquellas personas que aportaban una limosna para sufragar los gastos de la octava.

A continuación, los diputados concejiles procedian a la preparación del escenario de la fiesta. Este se componía de dos partes: el edificio sagrado o templo y el exterior sacralizado o calles por donde discurría la procesión.

En el interior del templo se montaban altares de madera para colocar las imágenes y tribunas para los músicos y las autoridades. Igualmente, se daba un especial barrido a la iglesia, se limpiaban las lámparas de araña y candeleros y se adornaban las bóvedas y el altar con guirnaldas hechas de tela y papel (19). Estas tareas las realizaban el sacristán, los monaguillos y otros mozos eclesiásticos (incluido el enterrador), los cuales, sobre todo el primero, obtenían un sobresueldo considerable por su trabajo. También el campanero percibía el suyo por iluminar el campanario y tocar durante todo el periodo festivo.

En cuanto a la preparación de las calles y plazas de la localidad se procedía a la limpieza sistemática para proseguir con el regado del itinerario de la procesión; en especial la plaza de la Iglesia y la calle Palacio (20). Estas medidas higié-

(18) A.M.P., A.C., cabildo 6-VIII-1750, f. 239. Un posterior Real Despacho de S.M. y Consejo de Castilla, fechado el 23-X-1750, sancionó dicho acuerdo. Cabildo 21-XI-1750.

(19) En 1736 se gastaron 205 reales en belillo, garzotas de papel y otros adornos. A.M.P., Leg. 849, Propios y Arbitrios, cuentas de 1736.

(20) Dicho itinerario nos aparece en A.M.P., P.A., Leg. 69, Exp. 1, año 1681. No hemos localizado ningún otro recorrido en la documentación consultada. 
nicas, normales hoy en dia pero excepcionales en aquella época, se completaban con una iluminación extraordinaria de la ciudad o parte de la misma. Como mínimo de la fachada del ayuntamiento ubicado en la plaza de la Iglesia. Esta iluminación se estableció a partir de 1734 al acordar el concejo municipal que...

"en honra y gloria de la Virgen Santísima de los Milagros su adorable Patrona titular y en reconocimiento de los beneficios recibidos de su divina mano todos los años, desde hoy en adelante, perpetuamente, se pongan luminarias en toda la ciudad la víspera de su santo día" (21).

En lo que a los religiosos propiamente dichos se refiere, encontramos, por un lado, a la diputación de fiestas organizando detalles complementarios, y por otro, al ayuntamiento en pleno, como corporación, asistiendo y participando en ellos.

Así el cabildo municipal concurría a las vísperas que se cantaban el día 7 a las cuatro de la tarde. Y ya el día 8 a los maitines del amanecer y a la celebración litúrgica que tenía lugar a las nueve de la mañana (22). Ese mismo día, a las cinco de la tarde, se iniciaba el desfile procesional, en el que tomaban parte un mínimo de nueve capitulares: "seis en las varas del palio, uno en el guión y dos con los bastones de gobierno" (23). Aunque lo normal es que comparecieran algunos más, asi como otras autoridades residentes en la localidad (ejército, hacienda, justicia), los oficiales y trabajadores municipales y las viudas de estos últimos y de los antiguos regidores. Toda esta representación concejil portaba cirios que eran sufragados por el ayuntamiento.

Finalizado el día festivo comenzaba la octava de la Virgen, encargándose la diputación de fiestas municipal, en aquellos años que le correspondía por la alternancia, de seleccionar a los posibles predicadores, contactar con ellos y cuidar de todo lo relacionado con el traslado, alojamiento, manutención y remuneración de los mismos. Se intentaba, dentro de las posibilidades económicas, conseguir los predicadores más famosos y cualificados, pertenecientes, en su gran mayoría, al clero regular.

Para terminar, comentaremos los actos profanos, no religiosos, que el ayuntamiento organizaba paralelamente y en concordancia con la festividad de la Patrona.

En primer lugar tenemos un acto de tipo privado, en el que sólo participan los miembros de la corporación y unos pocos invitados. Se trata de un pequeño ágape o convite celebrado al término del desfile procesional (24). En un principio, tenía un carácter bastante frugal, ya que sólo se consumían algunas bebidas y dulces. Concretamente, en 1713 se tomaron tres garrafas de agua, un frasco de

(21) A.M.P., A.C., cabildo 6-IX-1734, f. 221.

(22) Este horario en A.M.P., A.C., cabildo 18-VIII-1735, f. 173.

(23) A.M.P., A.C., cabildo 6-IX-1737, f. 148. Si por causas justificadas no habia disponible este número de regidores, se invitaba a caballeros particulares que los sustituyeran, para así evitar "la censura de imnumerables forasteros que concurren a la función".

(24) Tenemos constancia de este tipo de celebraciones festivo-gastronómicas en otras localidades y desde fechas mucho más tempranas. Así, el cabildo sevillano celebraba, ya en el siglo XV, un convite tras la procesión del Corpus. ROMERO ABAO, Antonio: "La fiesta del Corpus Christi en Sevilla en el siglo XV", en ALVAREZ; BUXO; RODRIGUEZ: Op. cit., Tomo III, pp. 26-27. 
vino y dulces. Con el paso del tiempo se hizo más consistente. Así, en 1718 se tomaron 12 libras $(5,5 \mathrm{Kg}$.) de bizcochos, 8 libras $(3,7 \mathrm{Kg}$.) de panales, 98 libras $(45,1 \mathrm{Kg}$.) de dulces, 3 garrafas de distintas bebidas frescas, 1 garrafa de agua y un frasco de vino. Durante un periodo de tiempo, que transcurre entre $1760 \mathrm{y}$ 1819 , no tenemos noticias del convite, por lo que sospechamos que fue suspendido ante las órdenes gubernamentales que exigían una restricción del gasto. En 1820 vuelve a aparecer el convite, conformándolo en esta ocasión 4 libras $(1,8$ Kg.) de panales, 4 de bizcochos, 6 botellas de licor, 12 de vino superior y agua de nieve (25).

Del mismo modo, dentro de estos actos lúdicos tenemos los de carácter público, que, por cierto, no eran muy abundantes. Era costumbre, al menos tras la incorporación en 1729, el levantar un castillo de fuegos artificiales que era quemado la víspera de la festividad de la Virgen de los Milagros, como una especie de anuncio estruendoso e impactante de la misma. Por otro lado, de forma esporádica, aquellos años que se contaba con un mayor presupuesto, se contrataba a algún grupo de danza, así uno gallego en 1729 , o a una pequeña orquesta de cámara, que solía venir a El Puerto desde Cádiz, como ocurrió en 1736, o desde Jerez, lo que sucedió en 1785 . En verdad, la música nunca faltaba en la fiesta, procesión y octava de la Patrona, ya que para ello, desde 1723 , el ayuntamiento había establecido un convenio con la capilla de música de la iglesia, a la que satisfacería 1500 reales anuales, por tocar en dichos actos y en otros festivos del año (26).

En resumen, el ayuntamiento, bien directamente o a través de la diputación de fiestas, interviene en la festividad de la Patrona, los años que le correspondía, preparando el programa de actos, acondicionando el templo y el espacio urbano para la fiesta, asistiendo a los actos religiosos, y organizando la octava y los espectáculos públicos de carácter profano. Sin olvidar, la celebración particular de la festividad por el cabildo mediante el convite privado.

\section{B. EL AYUNTAMIENTO Y LA FINANCIACION DE LA FESTIVIDAD DE LA VIRGEN DE LOS MILAGROS}

Ya hemos visto como por la ley o por la costumbre era habitual que el ayuntamiento sufragara los gastos ocasionados por un número determinado de festividades religiosas (27).

Durante el siglo XVIII, especialmente en su primera mitad, estos gastos fueron aumentando considerablemente debido a una conjugación de factores, entre los que sobresalen: el alza de una religiosidad cada vez más popular y basada en las devociones a los santos, lo que hace proliferar los actos dedicados a ellos; la favorable situación económica, que permite y, a la vez, obliga a realzar la suntuo-

(25) Todos estos datos en A:M.P., Propios y Arbitrios, Legs. 843 y 848.

(26) :A.M.P., A.C., cabildo 29-XI-1723, f. 115.

(27) Véase nota 3. Según CUESTA MARTINEZ, Manuel: La ciudad de Córdoba en el siglo XVIII, Córdoba, 1985, p. 120, "en el siglo XVII, a pesar del escandaloso déficit de su hacienda, el ayuntamiento de Córdoba subvencionaba con cantidades fijas parte del coste de algunas fiestas religiosas que se celebraban en la ciudad". En concreto 11.250 reales en 6 festividades. 
sidad de las festividades (28); y, por último, el afán de los gobernantes locales por impresionar a sus convecinos y ganarse los elogios de éstos por la organización de los festejos.

Un ejemplo de este mayor gasto nos lo ofrece la propia ciudad portuense, ya que si en el primer tercio del siglo XVIII su ayuntamiento gastaba en festejos unos 7.000 reales de media al año, durante el segundo tercio esa media anual ascendió hasta los 14.600 reales, es decir, se duplicó la cantidad (29).

Pero a partir del tercer tercio del siglo XVIII se va a producir un cambio drástico en este aspecto de la financiación municipal de las fiestas, ya que las aportaciones del ayuntamiento se verán mermadas considerablemente. Este cambio no se debe a una caída de la religiosidad, a un empeoramiento de la economía, o a una modificación de la mentalidad de los gobernantes locales. Las causas hay que buscarlas en las nuevas directrices políticas, de caracter ilustrado y utilitaristas, propugnadas por los miembros del gobierno de Carlos III. EI desarrollo y puesta en ejecución práctica de dichas directrices conlleva la promulgación de una serie de disposiciones que afectan directamente a los festejos celebrados en las localidades. De estas disposiciones destacan dos bloques:

a) las de orden público, que tendían a "suprimir o transformar ciertas manifestaciones barrocas de la piedad popular que no estaban de acuerdo con la mentalidad de los ilustrados" (30).

b) y las hacendísticas, que pretendian reorganizar, sanear y controlar las haciendas locales, atendiendo, sobre todo, a la contención del gasto público (31).

Las primeras reducen el número de festejos y las segundas limitan los gastos municipales en ellos. Fijémonos, ya que nos estamos ocupando de la financiación de las festividades, en estas últimas medidas.

Como consecuencia del desarrollo del artículo III de la Real Instrucción de 30 de julio de 1760 para la mejor administración de las haciendas municipales, el Consejo de Castilla, máximo organismo gubernamental, va a remitir a todos los municipios un reglamento de "gastos e ingresos", que no es sino un presupuesto municipal de obligado cumplimiento. Todos los reglamentos presentan un esquema uniforme. Comienzan con una relación de los propios y arbitrios que constituyen los recursos hacendísticos locales, dando el producto anual medio de cada ingreso en base a lo redituado en el último quinquenio. Y continúan con la enumeración de los diferentes gastos o cargas concejiles permitidas, agrupadas en cinco grandes partidas: los salarios, los censos, las FESTIVIDADES DE IGLESIA, los gastos eventuales y extraordinarios alterables fijos y los gastos eventuales y extraordinarios no fijos.

(28) NUÑEZ ROLDAN, Francisco: "Haciendas municipales en el reino de Sevilla a mediados del siglo XVIII", Historia, Instituciones. Documentos, 12, 1985, p. 112, relaciona la abundancia o carencia de fiestas con los elevados o escasos ingresos municipales respectivamente.

(29) Para el primer tercio hemos tomado los datos de 1713, 1714, 1718 y 1720. Para el segundo tercio los de $1750,1755,1760$ y 1765 . A.M.P., Propios y Arbitrios, Legs. 848-851.

(30) DOMINGUEZ ORTIZ, Antonio: Sociedad y Estado en el siglo XVIII español, Barcelona, 1976, p. 364 .

(31) Sobre estas reformas hacendísticas GONZALEZ BELTRAN, Jesús Manuel: Reformismo $y$ administración local en la provincia de Cádiz durante el reinado de Carlos III, Jerez de la Frontera, 1991, Cap. III. 
El reglamento o presupuesto de la ciudad de El Puerto de Santa María fue aprobado por el Consejo de Castilla el 16 de diciembre de 1768 , siendo recibido por el cabildo portuense el 11 de enero de 1769 (32). En él se estipulaban unos ingresos anuales de 237.515 reales y se permitían unos gastos por la cantidad de 124.065 reales, de los cuales sólo un $7 \%, 8.766$ reales, se destinarían a sufragar las festividades de iglesia (33). Es decir, el reglamento rebajaba en un $40 \%$, casi a la mitad, la cantidad que el ayuntamiento venía gastando de media en los últimos años en los festejos religiosos con participación municipal. Las protestas del concejo portuense tan sólo consiguieron modificar levemente el reglamento, obteniendo para la partida de fiestas un incremento, en 1773, de 1.092 reales, por lo que el montante total se elevaba hasta los 9.858 reales, manteniéndose el porcentaje en el $7 \%$ de todos los gastos. Porcentaje muy significativo si lo comparamos con los de otras ciudades, algo que podemos apreciar en el cuadro 1 (34), aunque la cantidad absoluta queda algo alejada de la media resultante.

Los 9.858 reales destinados a fiestas se deberían distribuir, según el Consejo de Castilla, de la siguiente forma: 4.400 reales para el Corpus Christi; 458 en la función de la Candelaria; 348 en la de la Concepción; 400 en la de Todos los Santos; 276 en la de S. Sebastián; 150 en la de S. Francisco Javier; 100 en la de Desagravios; 66 en la de S. Marcos; 60 en la de Nuestra Señora de las Mercedes; 300 en otras fiestas obligadas (Semana Santa); y 3.300 en la festividad de la Virgen de los Milagros, el 33,5\% de todo el presupuesto festivo, lo cual da una idea de la importancia que la festividad patronal tenía en la localidad y el fuerte apoyo económico que recibía del ayuntamiento portuense (35).

Ahora bien, ¿eran suficientes para sufragar los gastos de la festividad de la Virgen de los Milagros esos 3.300 reales anuales señalados por el Consejo de Castilla en 1768 ?. La respuesta para ese momento concreto era negativa, pero no siempre se habían desembolsado tantos caudales en la festividad de la Patrona. Veamos, con la ayuda del cuadro 2, una evolución de los gastos de la fiesta patronal entre 1675 y 1825.

Tenemos un primer periodo comprendido entre 1675 , fecha de inicio de nuestra investigación, y 1731, año significativo por cuanto en él se configura el nuevo gobierno municipal tras la incorporación a la Corona $y$, como vimos, se llega al acuerdo ayuntamiento-clero de sufragar los gastos de la octava en años

(32) A.M.P., A.C., cabildo 11-I-1769, f. 22.

(33) Un ejemplar del reglamento portuense en A.M.P., Sección Papeles Varios, 3, ff. 43-52v..

(34) Los datos del cuadro 1 obtenidos de: MACIAS, A.M.: "Aportación al estudio de las haciendas lócales: los presupuestos del ayuntamiento de La Laguna (1772-1851)", Revista de Historia Canaria, XXXVII, 1983, p. 142; INFANTE, Javier: El municipio de Salamanca a finales del Antiguo Régimen, Salamanca, 1984, p. 37; MARINA BARBA, Jesús: "El ayuntamiento de Granada y la reforma de las haciendas locales en el siglo XVIII", Chronica Nova, 17, 1989, pp. 212-213; BERNAL, A.M.: "Haciendas locales y tierras de propios: funcionalidad económica de los patrimonios municipales (ss. XVI-XIX)", Hacienda Pública Española, 55, 1978, p. 292; A.M. Cádiz, A.C., cabildo 19-I-1765; A.M. Medina, A.C., cabildo 25-VI-17.77; A.M. Jerez de la Frontera, A.C., cabildo 10-V-1765, ff. 119-142; y A.M.P., Papeles Varios, 3, ff. 43-52v.

(35) La Virgen de la Candelaria, Patrona de Medina, absorbía el 14\% del presupuesto de fiestas de dicha localidad. La. Virgen de la Merced tan sólo el 2,7\% de los gastos festivos de Jerez. Y la Virgen del Rosario un mínimo 1,1\% del presupuesto para fiestas del Ayuntamiento de Cádiz. 
alternos, sin la intervención de vecinos particulares. En esta primera etapa las aportaciones municipales son escasas, presentando una media anual en torno a los 550 reales. Esa exigua cantidad viene dada por la suma de los 400 reales que daba el ayuntamiento de limosna a la persona o institución que organizara la octava (36), y lo que costara el convite privado de los ediles. La escasa financiación por parte del cabildo municipal está íntimamente relacionada con la nula o mínima participación en la organización de los festejos, que generalmente, durante estos años, corre a cargo de distintos vecinos acaudalados.

Entre 1731 y 1769 , primer año en el que está en vigor el reglamento o presupuesto de gastos e ingresos, discurre un segundo periodo en el que los desembolsos municipales en la festividad de la Patrona van a ser especialmente cuantiosos. La media de gasto anual se sitúa en torno a los 7.000 reales, cantidad muy elevada si tenemos en cuenta, además, que sólo uno de cada dos años corría el ayuntamiento con la totalidad del costo. Es decir, el año que el concejo municipal organizaba la fiesta y octava se gastaba en torno a 13.000 reales de los caudales públicos, a los que habría que añadir otras cantidades aportadas por limosnas por los vecinos (37).

¿A qué se debe este aumento tan considerable del gastos?. La respuesta viene determinada por el hecho de la instauración del nuevo concejo municipal portuense tras la incorporación de la ciudad a la Corona. Los nuevos componentes del ayuntamiento, personas que habían adquirido mediante compra los cargos que desempeñaban, no dudaron en gastar más y más cada año en unas fiestas públicas, especialmente, por su significación y raigambre popular, en la de la Patrona, que les permitian mostrarse al vecindario como grupo dominante de la sociedad y, a la vez, como detentador del poder político. Igualmente, hay que tener en cuenta que todos estos nuevos capitulares son componentes de la élite socio-económica de la localidad y que intentan, utilizando para ello los caudales públicos, dar a los festejos un boato y una magnificencia en consonancia con los del estilo de vida del grupo social al que pertenecen.

¿Cómo se distribuían esos 13.000 reales que el ayuntamiento gastaba en la festividad de la Patrona los años que organizaba la fiesta y octava?. Es difícil responder a esta pregunta, ya que en la contabilidad de este periodo, 1731-1769, aparece el montante total de lo desembolsado para las fiestas patronales, pero no lo correspondiente a cada gasto particular. No es de extrañar que este tipo de contabilidad global tratara de ocultar gastos superfluos e, incluso, algunos de dudosa legitimidad. No obstante, podemos realizar una aproximación a la distribución del gasto gracias a las cuentas detalladas que hemos localizado correspondientes al año 1736. En ellas podemos descubrir, ver cuadro 2, una subida generalizada de todos los desembolsos, a excepción de los relativos a organización y preparación de la vía pública. Pero sobresalen, especialmente, las partidas correspondientes a la cera consumida, tanto en las luminarias como en la procesión, y a

(36) MORGADO GARCIA, Arturo: Iglesia y sociedad en el Cádiz del siglo XVIII, Cádiz, 1989, p. 209 , indica la existencia de esta costumbre en la vecina ciudad de Cádiz, otorgando el ayuntamiento 1.100 reales anuales de limosna a la cofradía de Nuestra Señora del Rosario.

(37) Así, por ejemplo, en 1746 el alferez mayor, D. Guillermo Tyrry, ofreció la inusual cantidad de 1.500 reales. A.M.P., A.C., cabildo 15-VI-1746, f. 97. 
los gastos ocasionados por los actos lúdicos, no estrictamente religiosos, que completaban el programa festivo. En concreto, los 7.520 reales invertidos en esta última partida en 1736 alcanzaban el $48 \%$ del gasto total. Esta cantidad se dividia en 2.158 reales abonados al maestro cohetero por los fuegos artificiales; 2.200 reales pagados a la capilla de música de la iglesia por su participación en las funciones de la octava; y 3.162 reales entregados a los cantores y músicos de Cádiz por el iconcierto público ofrecido el día de la Virgen de los Milagros (38).

Finalmente, en este estudio que estamos realizando de la financiación, tenemos un tercer periodo que discurre entre 1769 , con el reglamento ya en vigor, y 1825, año límite de nuestra investigación. Durante esta etapa, como ya vimos, la aportación municipal para la festividad y la octava de la Virgen de los Milagros no podía superar, tal como estipulaba el reglamento de gastos e ingresos o presupuesto, los 3.300 reales al año. En 1769, al corresponder la organización y financiación de los festejos al clero, la drástica reducción no tuvo repercusión alguna. Fue en 1770 cuando el ayuntamiento se dió perfecta cuenta de que sólo se le permitía gastar en las fiestas patronales en torno a un $25 \%$ de lo que venía gastando habitualmente. En un informe presentado al pleno del ayuntamiento por una comisión de capitulares en el mes de mayo se exponía que para "realizar la función de los Milagros icon la decencia necesaria" eran precisos un mínimo de 8.360 reales, cantidad muy superior a los 3.300 permitidos (39). Las cuentas municipales de 1770 nos descubren como el concejo local intentó limitar el gasto al máximo, recortando partidas como las correspondientes a la cera, pago de los predicadores y música, y llegando a suprimir el convite privado de los munícipes en honor de la Virgen. A pesar de todo, los gastos ascendieron a 6.722 reales, a los que tenemos que descontar los 3.248 aportados de limosna por los vecinos, por lo que el ayuntamiento sólo tuvo que desembolsar 3.474 reales, cantidad ligeramente superior a la establecida en el reglamento.

Los problemas volvieron a surgir en 1772 , el siguiente año que correspondía al concejo local la organización de los festejos: Los diputados de fiestas se quejaban de la falta de caudales y propusieron como solución una argucia legal-contable: el ayuntamiento aportaría cuando le tocara financiar la festividad 6.600 reales, "los 3.300 que marca' el reglamento y los 3.300 del año que la fiesta corre a cargo del clero" (40). La propuesta fue aceptada por el cabildo y no contradicha por las autoridades estatales, lo que unido a la utilización de fondos destinados a otros festejos para sufragar la fiesta de la Patrona y a las ayudas aportadas por particulares desinteresada o interesadamente (41), permitió que la festividad de la Virgen de los Milagros se siguiera celebrando con relativa suntuosidad. A través del estudio de las cuentas de algunos años del periodo, ver cuadro 2 , hemos podido comprobar como el ayuntamiento se gastaba, cuando corría con la organización de los actos, una media de 5.300 reales a los que debemos añadir otros 1.000 rea-

(38) Las cuentas de 1736 en A.M.P., Propios y Arbitrios, Leg. 849.

(39) A.M.P., A.C., cabildo 9-V-1770, ff. 134-152.

(40) A.M.P., A.C., cabildo 28-VII-1772, f. 189.

(41) Así, en 1774 el asentista de la plaza de toros ofreció un donativo de 2.000 reales para los festejos siempre que las autoridades locales le permitieran dar cuatro regocijos o novilladas. El ayuntamiento aceptó. A.M.P., A.C., cabildo 17-VIII-1774, f. 260. 
les gastados el año que no le correspondía dicha organización. Es decir, cada dos años el desembolso total rondaba los 6.500 reales, cantidad que dividida por dos viene a resultar, aproximadamente, la establecida por las autoridades estatales a través del reglamento de gastos e ingresos. Por tanto, el ayuntamiento, aunque con una pequeña trampa legal, cumplía estrictamente lo preceptuado.

Para limitar los gastos, el concejo municipal suprimió, definitivamente, el convite privado de los ediles y los fuegos artificiales. Igualmente, redujo el costo de los predicadores de la octava, lo cual pudo redundar, tal vez, en una inferior calidad de los sermones. En cuanto al acompañamiento musical, el ayuntamiento procuró que no se viera afectado por la reducción de caudales, algo que queda demostrado en la documentación. Se siguió contando, como mínimo, con la capilla de música de la iglesia, a cuyo frente se encontraba el maestro José Martí. Y cuando era posible se traían voces y músicos de otras poblaciones, los cuales cobraban unos estipendios muy altos por sus actuaciones. Un ejemplo, en $1785 \mathrm{el}$ ayuntamiento contrató, además de a la capilla de música por 1.500 reales, a un vocalista de Jerez de la Frontera, dos violines, dos trompas, un oboe, un bajo y un contrabajo, todos por 1.290 reales (42). La cuestión de por qué no se limitaban los gastos de la partida musical creemos que se debe a una posible competencia con el cabildo eclesiástico, que no dudaba en invertir más de 5.000 reales en este concepto, contratando más músicos y mejores. Así, en 1789 reunió a la capilla de música de la iglesia, dos vocalistas, cinco violines, dos trompas, un oboe, un contrabajo y una viola, de los cuales la primera voz y el primer violín cobraban 600 reales cada uno (43).

Para acabar con estas rivalidades y otros problemas anexos a la festividad de la Patrona, los cabildos municipal y eclesiástico acordaron en 1823 organizar la fiesta y octava de la Virgen de los Milagros conjuntamente, sufragando los gastos generales por mitad (44). Con esta medida el más beneficiado era el ayuntamiento, no porque tuviera que aportar menos dinero, sino porque evitaba comparaciones odiosas del vecindario entre unos actos preparados por un concejo municipal con unos gastos limitados y otros actos dispuestos por un clero con una cierta liberalidad económica y por lo tanto más suntuosos y llamativos (45).

En definitiva, este trabajo de investigación nos muestra como todos los aspectos de la sociedad, en este caso concreto la festividad de la Patrona, están impregnados del conjunto de características que definen a dicha sociedad en cada momento temporal específico. La fiesta de la Virgen de los Milagros en El Puerto de Santa María del siglo XVIII se nos presenta estamental y oligárquica. Es decir, dominada por los grupos dirigentes de la sociedad portuense, que no dudan en utilizarla en provecho propio para mostrarse e impresionar al resto del vecindario.

(42) A.M.P., Propios y Arbitrios, Leg. 854.

(43) Archivo Iglesia Mayor Prioral de El Puerto de Santa María, Caja 505, cuentas del clero, año 1789.

(44) Ibidem, año 1823.

(45) El clero para sufragar los gastos contaba con las abundantes limosnas y con la devolución de los impuestos indirectos que pagaban (refacción). Pero era normal que los dos eclesiásticos que formaran la diputación de fiestas pusieran de su bolsillo entre 2.000 y 5.000 reales para completar los pagos. 
Igualmente, se puede observar claramente el intento de un sector reducido del grupo dominante local, en concreto los miembros del ayuntamiento, por apartar de la organización de los actos patronales a posibles competidores (vecinos acaudalados y clero) y, en consecuencia, monopolizar una fiesta tan significativa para la población. Por último, vemos como la intervención estatal, con el aspecto de reformas hacendísticas, poniendo límites a los gastos, perjudica a los intereses de los capitulares y les coarta su libertad de acción, obligándoles a replantearse su posición en la organización y, sobre todo, en la financiación de la fiesta patronal. 
CUADRO 1

Cantidades y porcentajes señalados para Fiestas en los Reglamentos de varias ciudades

\begin{tabular}{lccccccccc} 
Ciudades & La Laguna & Salamanca & Granada & Sevilla & Cádiz & Medina & Jerez & El Puerto & Media \\
\hline Cantidad (en reales) & 13.797 & 5.216 & 47.163 & 25.786 & 40.345 & 5.370 & 8.920 & 9.858 & 19.556 \\
Porcentaje & 8,7 & 3,4 & 18,8 & 1,7 & 6,6 & 10,3 & 5,0 & 7,0 & 7,7
\end{tabular}

\section{CUADRO 2}

Financiaciôn de la Festividad de la Virgen de los Milagros por el Ayuntamiento Evolución del gasto por partidas (en reales de vellón)

\begin{tabular}{lrrrrrrrrrrrrrrrrr} 
Años & $\mathbf{1 6 7 9}$ & $\mathbf{1 6 8 7}$ & $\mathbf{1 7 1 3}$ & $\mathbf{1 7 2 0}$ & $\mathbf{1 7 2 9}$ & $\mathbf{1 7 3 5}$ & $\mathbf{1 7 3 6}$ & $\mathbf{1 7 4 5}$ & $\mathbf{1 7 5 0}$ & $\mathbf{1 7 6 0}$ & $\mathbf{1 7 6 5}$ & $\mathbf{1 7 7 0}$ & $\mathbf{1 7 7 5}$ & $\mathbf{1 7 8 0}$ & $\mathbf{1 7 8 5}$ & $\mathbf{1 8 2 0}$ & $\mathbf{1 8 2 5}$ \\
\hline Tipo de & & & & & & & & & & & & & & & \\
Gasto & & & & & & & & & & & & & & \\
P1. & 0 & 0 & 26 & 30 & 66 & - & 367 & 30 & - & - & - & 143 & 40 & 369 & 40 & 616 & 922 \\
P2. & 86 & 0 & 0 & 0 & 72 & - & 1.688 & 8 & - & - & - & 680 & 398 & 1.180 & 547 & 1.294 & 870 \\
P3. & 190 & 0 & 0 & 0 & 0 & - & 2.657 & 0 & - & - & - & 1.563 & 200 & 2.625 & 231 & 2.620 & 3.088 \\
P4. & 200 & 0 & 400 & 400 & 0 & - & 2.063 & 400 & - & - & - & 1.366 & 400 & 1.840 & 400 & 1.582 & 1.902 \\
P5. & 0 & 0 & 0 & 0 & 300 & - & 7.520 & 0 & - & - & - & 2.970 & 0 & 0 & 2.790 & 2.280 & 1.800 \\
P6. & 0 & 215 & 331 & 119 & 297 & - & 1.339 & 438 & - & - & - & 0 & 0 & 0 & 0 & 202 & 0 \\
Totales & 476 & 215 & 757 & 549 & 735 & $10.942(1)$ & $15.634(2)$ & 876 & 9.010 & 17.080 & 1.533 & $6.722(3)$ & 1.038 & 6.014 & 4.008 & 8.594 & $8.582(4)$
\end{tabular}

(1) Aportación municipal 2.917 reales, el resto de limosnas.

(2) Aportación municipal 13.842 reales, el resto de limosnas. Visita del Arzobispo.

(3) Aportación municipal 3.474 reales, el resto de limosnas.

(4) Aportación municipal 4.291 reales, la otra mitad del clero. 